\title{
On the entropy production of the constructal plate generating heat
}

\author{
Patrick Ribeiro*, Diogo Queiros-Condé \\ 50, rue de Sèvres, 92410 Ville d'Avray, France
}

\begin{abstract}
In this paper, the elemental construct of an I-shaped fin cooling a heat generating volume is studied through the entropy production perspective. Using the constructal design method framework with entropy production minimization as an objective leads to different optimal shape ratio, different from the ones obtained using the excess of temperature. Moreover, the optimal shape ratio evolution is not necessary the same for local entropy production minimization (excess of entropy production) and global entropy production (entropy produced in the whole area). Finally, an analysis on a possible dimensionless number is introduced for the study of constructal plates.
\end{abstract}

Keywords: Constructal theory, Entropy production, Thermal science, Thermodynamics, entropy production

\section{Introduction}

Thermodynamics has been originally and is still nowadays used to study fluxes of mass, energy and entropy flowing through a system and its boundaries. Convenient quantities or methods have been used to better understand phenomena and to deal with optimization. Exergy, entropy production minimization or finite thermodynamics are popular quantities and methods beeing very used in science $[1,2,3]$.

Constructal theory has been initially used in transportation sciences (focused on street network theory [4]) and thermal sciences (more precisely in the cooling of a heat generating area [5]). Since then, many other fields have

\footnotetext{
*Corresponding author.

Email address: patrick.ribeiro@parisnanterre.fr (Patrick Ribeiro)
} 
been interested in constructal theory leading to applications from engineering to nature $[6,7,8,9,10,11,12,13,14,15,16,17,18,19,20,21]$.

In contrast with the classical thermodynamic principles, the constructal theory gives high importance to geometry. Indeed, the constructal theory is a physics principle which takes into account the significance of geometric orientation of fluxes and their configuration in the phenomenon under study. This physical principle is based on the fact that the configuration evolves to offer greater access to what flows in the system [22, 23, 24].

Arising from the constructal theory, the constructal design method permits to get the best geometrical configuration of flows in the system from specific objectives and constraints i.e. to obtain the optimal architecture of flows. The constructal design studies shapes from an elemental object until larger objects (opposite of the fractal reasoning), it is thus a method involving multiple scales. Certain shapes have been bounded to particular geometries like parabolic fractality related to scale dependence [25, 26, 27].

Based on constructal design, several works permitted to obtain optimal configurations: for latent thermal energy storage [28, 29, 30, 31], for pedestrian evacuation $[32,33]$, for heat exchangers [34, 35, 36], to enhance thermal performance of systems under convection [37, 38, 39, 40, 41, 42, 43, 44, 45] and conduction $[46,47,48,49,50,51,52,53]$.

On the heat generating area problem in particular, analytical developments for simple I-shaped conductive strip morphologies have been obtained $[54,55,56,57,58]$. Besides I-shaped studies, various configurations have been analysed on the variation of morphologies of the conductive strip $(+$, H, X, Y, V, Fork shapes) $[59,60,61,62,63,64,65]$ with thermal contact resistance (I,T shapes) [66, 67], considering size effect on conductivity of the conductive strip and considering nonuniform heat generation in the area $[68,69,70,71,72]$. Some methods to obtain the shape of the conductive strip have also been investigated $[73,74,75,76]$.

Other developments related to the second principle such as irreversible process, equipartition of dissipation and entropy production were conducted $[77,78,79]$. To expand on the same developments, in this paper, we study an elemental construct of an I-shaped fin cooling a heat generating plate through entropy production.

In the first part, we recall the general result obtained using the minimization of the maximum excess of temperature. Then, we focus on the second law analysis to obtain the entropy production generated by the generalised constructal model in stationnary state. It permits to obtain the 
optimal shape ratio using the minimization of the maximum excess of entropy production as well as the optimal shape ratio using the minimization of the entire entropy production. Finally, we study the applicability of known dimensionless numbers in the constructal heat generating plate.

\section{Optimal architecture of the elemental construct from minimiza- tion of the dimensionless maximum excess of temperature}

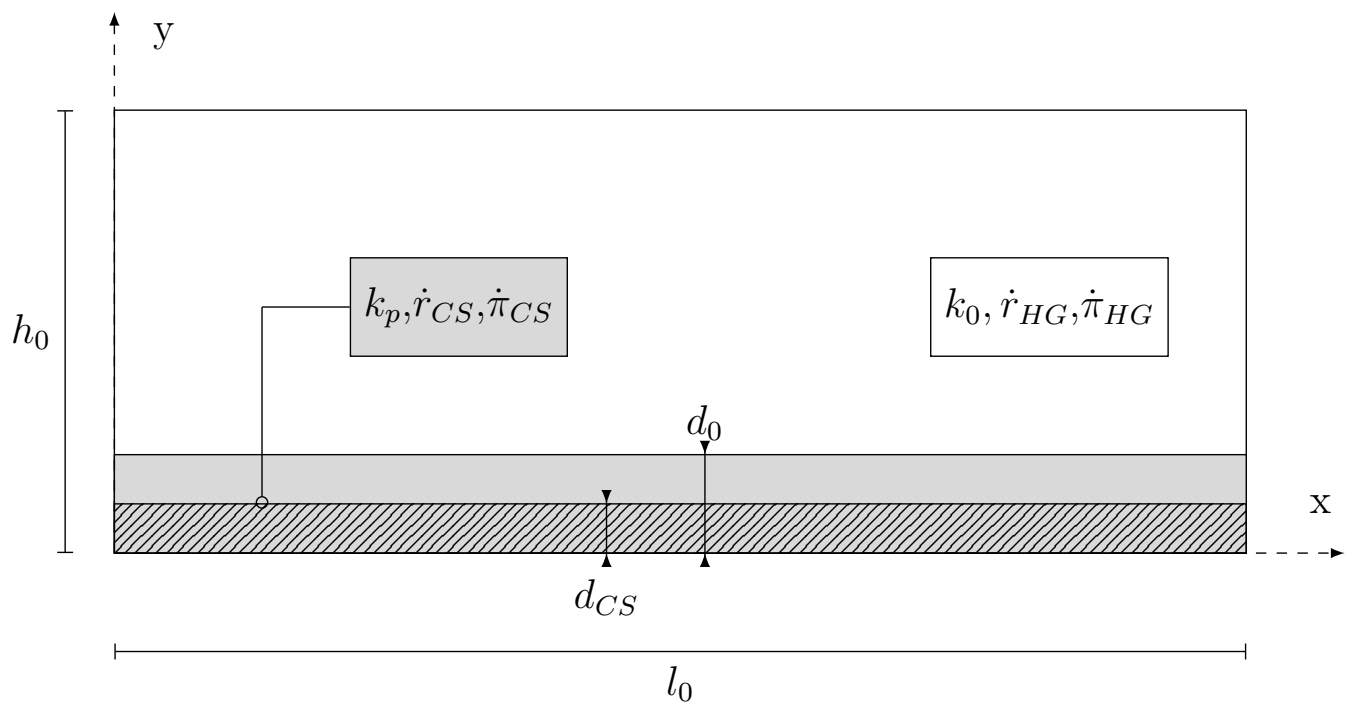

Figure 1: Elemental volume studied

The classical heat generating area problem implies a simple geometry detailed on fig.1. Taking into account heat production variability in the conductive strip, and assuming the validity of the slenderness hypothesis [80], the thermal model gives the following equations for the two different materials [58]:

$$
\begin{gathered}
k_{0} \frac{\partial^{2} T}{\partial y^{2}}+\dot{r}_{H G}=0 \quad \text { In the heat generating area } \\
\frac{\partial^{2} T}{\partial x^{2}}+\frac{\dot{r}_{H G}}{k_{p}}\left(\frac{h_{0}}{d_{0}}-\left(1-\frac{\beta}{n}\right)\right)=0 \quad \text { In the conductive strip } \\
\beta=\frac{\dot{r}_{C S}}{\dot{r}_{H G}} \geq 0 \quad n=\frac{d_{0}}{d_{C S}} \geq 1
\end{gathered}
$$


Where $\beta$ is the ratio of the amplitudes of heat generation in the two materials and $n$, the ratio of the conductive strip height to the conductive strip height generating heat.

The temperature field is then expressed:

$T(x, y)=\frac{\dot{r}_{H G}}{k_{0}}\left(\left(h_{0}-d_{0}\right) y-\frac{y^{2}}{2}\right)+\frac{\dot{r}_{H G}}{k_{p} \phi_{0}}\left(1-\phi_{0}\left(\frac{n-\beta}{n}\right)\right)\left(l_{0} x-\frac{x^{2}}{2}\right)+T_{0}$

And the shape ratio optimum is given by:

$$
\left(\frac{h_{0}}{l_{0}}\right)_{o p t, \Delta \tilde{T}}=\sqrt{\frac{\left(1-\phi_{0}\left(\frac{n-\beta}{n}\right)\right)}{\hat{k} \phi_{0}\left(1-\phi_{0}\right)^{2}}}=\sqrt{\frac{\kappa_{0}}{\hat{k} \phi_{0}\left(1-\phi_{0}\right)^{2}}}
$$

with $\hat{k}$ is the ratio of conductivities, $\phi_{0}$ the ratio of the height of the conductive strip to the height of the heat generating plate and $\kappa_{0}$ a writing simplification:

$$
\hat{k}=\frac{k_{p}}{k_{0}} \quad \phi_{0}=\frac{d_{0}}{h_{0}} \quad \kappa_{0}=\left(1-\phi_{0}\left(\frac{n-\beta}{n}\right)\right)
$$

\section{Local entropy productions of the constructal plate}

\subsection{Local entropy production}

A local analysis is possible using the classical form of the two principles in stationnary state where the sum of fluxes of a quantity through a closed surface is converted into a divergence in the volume, heat source and its associated entropy beeing represented by $\dot{r}$ and $\dot{R}$ :

$$
-\operatorname{div}(\varphi)+\dot{r}=0 \quad-\operatorname{div}(J)+\dot{R}+\dot{\Pi}=0
$$

The term $\dot{\Pi}$ corresponds to the irreversibility of the transformation, ie, the entropy generated during the process. Developing the second principle leads to:

$$
-\operatorname{div}(\varphi)+\dot{r}=0 \quad-\operatorname{div}\left(\frac{\varphi}{T}\right)+\frac{\dot{r}}{T}+\dot{\Pi}=\frac{-\operatorname{div}(\varphi)+\dot{r}}{T}-\varphi \cdot \nabla\left(\frac{1}{T}\right)+\dot{\Pi}=0
$$


The Fourier model is used for the heat flux conduction $\varphi=-k \nabla T$ and gives ( $\Delta$ and $\nabla$ being the Laplacian and Nabla operators) :

$$
k \Delta T+\dot{r}=0 \quad \dot{\Pi}=k\left(\frac{\nabla T}{T}\right)^{2}
$$

In our case, the entropy production can be separated in two distinct parts from each material recalling that flux orientation hypotheses are still used:

$$
\begin{gathered}
\dot{\Pi}=\dot{\Pi}_{H G A}+\dot{\Pi}_{C S} \quad \dot{\Pi}_{C S}=k_{p}\left(\frac{\nabla T_{x}}{T(x)}\right)^{2} \quad \dot{\Pi}_{H G A}=k_{0}\left(\frac{\nabla T_{y}}{T(x, y)}\right)^{2} \\
\dot{\Pi}_{H G A}=k_{0}\left(\frac{\frac{r_{\dot{H} G}}{k_{0}}\left[\left(h_{0}-d_{0}\right)-y\right]}{T(x, y)}\right)^{2} \quad \dot{\Pi}_{C S}=k_{p}\left(\frac{\frac{r_{H G} \kappa_{0}}{k_{p} \phi_{0}}\left[l_{0}-x\right]}{T(x)}\right)^{2}
\end{gathered}
$$

We can observe that the local entropy production is null at the extremities. Then, constructing a local entropy creation difference between the heat generating area and the conductive strip leads to the maximal excess of entropy production:

$$
\begin{gathered}
\Delta \dot{\Pi}=\Delta \dot{\Pi}_{C S}+\Delta \dot{\Pi}_{H G A}=\left[\dot{\Pi}_{C S}(0,0)-\dot{\Pi}_{C S}\left(l_{0}, 0\right)\right]+\left[\dot{\Pi}_{H G A}\left(l_{0}, 0\right)-\dot{\Pi}_{H G A}\left(l_{0}, h_{0}-d_{0}\right)\right] \\
\Delta \dot{\Pi}=k_{p}\left[\frac{\dot{r}_{H G} \kappa_{0} l_{0}}{k_{p} \phi_{0} T_{0}}\right]^{2}+k_{0}\left[\frac{\dot{r}_{H G} h_{0}\left(1-\phi_{0}\right)}{k_{0} T\left(l_{0}, 0\right)}\right]^{2}
\end{gathered}
$$

\subsection{Thermodynamic scale}

One can open a parenthesis on an interesting feature of the equation obtained for the maximal excess of entropy production. Indeed, the previous result can be rewritten differently introducing a thermodynamic scale:

$$
\Delta \dot{\Pi}=\frac{k_{p}}{L_{C S}^{2}}+\frac{k_{0}}{L_{H G A}^{2}}
$$

with:

$$
L_{C S}=\frac{T_{0}}{\left(T\left(l_{0}, 0\right)-T_{0}\right)}\left(\frac{l_{0}}{2}\right) \quad L_{H G A}=\frac{T\left(l_{0}, 0\right)}{\left(T\left(l_{0}, h_{0}-d_{0}\right)-T\left(l_{0}, 0\right)\right)}\left(\frac{h_{0}-d_{0}}{2}\right)
$$


Where we recognize a $C O P_{\text {cold }}$ in front of the two physical length scales of the plate.

An increase of the $C O P_{\text {cold }}$ implies an higher thermodynamic length resulting in a diminution in the entropy production difference. Thus, this thermodynamic length represents a distance to pure irreversibility i.e. the higher the thermodynamic scale the less the thermodynamic transformation is irreversible. This thermodynamic length can be represented as a spreading curve for small lengths corresponding to a dissipative trend for energy and a straight line for high lengths corresponding to a conservative trend ([81]).

We have seen here another possible bond between geometry and thermodynamics. We can now move on the local optimisation in terms of entropy production.

\section{Aspect ratio optimum}

\subsection{Local optimum}

We can observe that the local entropy production for each material are minimal and maximal at the extremities. For the conductive strip, we have $\max \left(\dot{\Pi}_{C S}\right)=\dot{\Pi}_{C S}(0,0)$ and $\min \left(\dot{\Pi}_{C S}\right)=\dot{\Pi}_{C S}\left(l_{0}, 0\right)=0$. Analogously, in the heat generating area, we have $\max \left(\dot{\Pi}_{H G A}\right)=\dot{\Pi}_{H G A}\left(l_{0}, 0\right)$ and $\min \left(\dot{\Pi}_{H G A}\right)=$ $\dot{\Pi}_{H G A}\left(l_{0}, h_{0}-d_{0}\right)=0$. It is thus possible to obtain a shape ratio minimizing this precise difference on local entropy. To simplify, we use:

$$
T\left(l_{0}, 0\right)=\alpha T_{0} \quad \alpha=\frac{\dot{r}_{H G} \kappa_{0} l_{0}^{2}}{2 k_{p} \phi_{0} T_{0}}+1
$$

The local entropy difference i.e. the maximal excess of entropy production is then:

$$
\Delta \dot{\Pi}=\left(\frac{\dot{r}_{H G}}{T_{0}}\right)^{2}\left[\left(\frac{\kappa_{0}}{\phi_{0}}\right)^{2} \frac{l_{0}^{2}}{k_{p}}+\left(\frac{\left(1-\phi_{0}\right)}{\alpha}\right)^{2} \frac{h_{0}^{2}}{k_{0}}\right]
$$

In the wake of the thermal analysis, we can construct a dimensionless maximal entropy production excess:

$$
\frac{\Delta \dot{\Pi}}{\left(\frac{\dot{r}_{H G}}{T_{0}}\right)^{2}\left(\frac{h_{0} l_{0}}{k_{0}}\right)}=\Delta \tilde{\pi}=\left[\left(\frac{\kappa_{0}}{\phi_{0}}\right)^{2} \frac{l_{0}}{h_{0} \hat{k}}+\left(\frac{\left(1-\phi_{0}\right)}{\alpha}\right)^{2} \frac{h_{0}}{l_{0}}\right]
$$


The shape ratio optimum is calculated considering the surface $A=\left(h_{0} l_{0}\right)$ to be constant, thus $\alpha$ becomes:

$$
\alpha=\frac{\dot{r}_{H G} \kappa_{0}\left(l_{0} h_{0}\right) l_{0}}{2 k_{p} \phi_{0} T_{0} h_{0}}+1=\underbrace{\frac{\dot{r}_{H G} \kappa_{0} A}{2 k_{p} \phi_{0} T_{0}}}_{P m}\left(\frac{l_{0}}{h_{0}}\right)+1
$$

$\alpha$ being a function of $l_{0} / h_{0}$, the derivative of the dimensionless maximal excess of entropy production is taken here related to $l_{0} / h_{0}$ leading to:

$$
\underbrace{\frac{\left(\frac{\kappa_{0}}{\phi_{0}}\right)^{2} \frac{1}{\hat{k}}}{\left(1-\phi_{0}\right)^{2}}}_{C}=\frac{\alpha^{-2}}{\left(\frac{l_{0}}{h_{0}}\right)^{2}}+\frac{2 \alpha^{\prime} \alpha^{-3}}{\left(\frac{l_{0}}{h_{0}}\right)}
$$

with:

$$
\left(\frac{l_{0}}{h_{0}}\right)=\frac{(\alpha-1)}{P m} \quad \alpha^{\prime}=P m
$$

The final equation reduces to:

$$
\frac{C}{P m^{2}}\left(\alpha^{5}-2 \alpha^{4}+\alpha^{3}\right)-3 \alpha+2=0
$$

The equation is solved numerically (with Newton's method) since there is no algebraic expression for quintic polynomials. Then the shape ratio solutions are obtained using eq.21 keeping only the real positive roots for $\alpha$.

Once the solution is obtained, one can use the ratio of the optimal length for entropy production to the optimal length for the temperature (eq.5) to illustrate the deviation of these two optimums:

$$
O_{r}=\frac{\left(\frac{l_{0}}{h_{0}}\right)_{o p t, \Delta \tilde{\pi}}}{\left(\frac{l_{0}}{h_{0}}\right)_{o p t, \Delta \tilde{T}}}
$$

The following range of parameters is used to obtain the evolution of the optimal aspect ratio:

$$
k_{0}=1 W m^{-1} K^{-1} \quad \hat{k} \in[20,2000] \quad \dot{r}_{H G} \in[1,1000] W^{-3}
$$




$$
\begin{gathered}
A \in[0.1,1] m^{2} \quad T_{0}=288.15 K \\
\phi_{0} \in[0.05,0.25] \quad n \in[1,25] \quad \beta \in[0,25]
\end{gathered}
$$

The deviation between these optimums is observable in fig.2, increasing with the parameter $\beta$ and decreasing with the parameter $n$. For the parameters $A$ and $\dot{r}_{H G}$, the deviation between the two optimums in the chosen range is negligible (recalling that the optimum in temperature is independent of these two parameters).
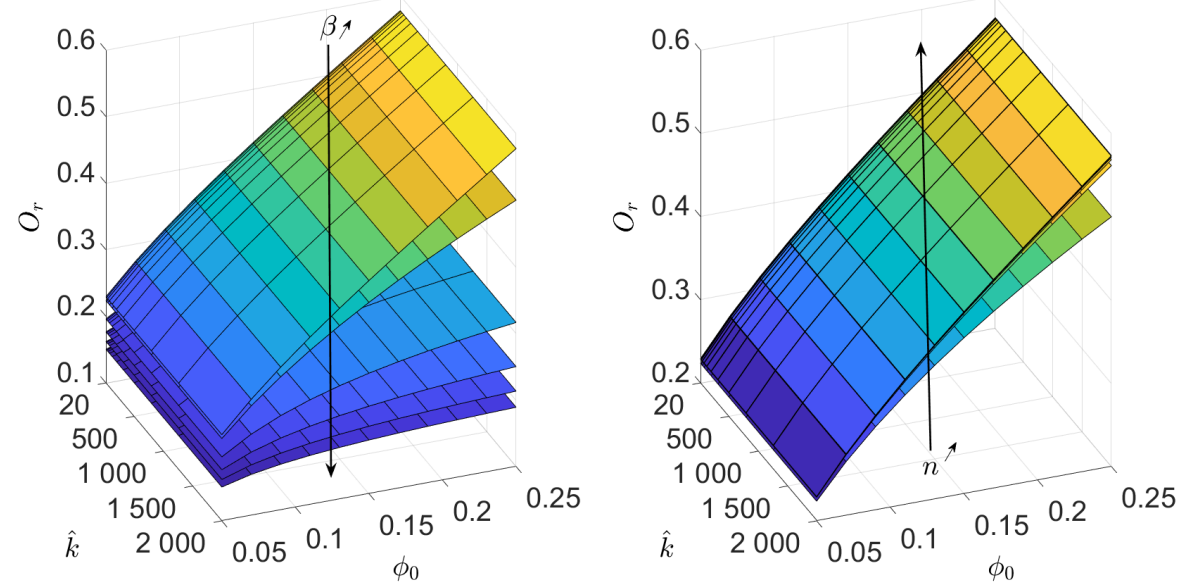

Figure 2: Ratio of the optimal length for entropy production to the optimal length for temperature (only real positive root)

For the given parameters, the solution of the quintic equation gives an optimum approximately vaying between 0.1 and 10 . Thus, we set:

$$
O=\left(\frac{l_{0}}{h_{0}}\right) \quad 0.1 \leq O \leq 10
$$

Using the preceding range, one can see the bifurcation of the optimal aspect ratio minimizing the non dimensional entropy production excess in fig.3. The principal parameters affecting the optimal aspect ratio are $\phi_{0}$ and $\hat{k}$, as well as $\beta$ and $n$ in a lesser extent. The parameters $\dot{R}_{H G}$ and $A$ affect marginally the aspect ratio.

We have seen here the evolution of the aspect ratio of the maximal excess of dimensionless entropy (which is a local quantity). However, since entropy production is an additive quantity, one can rather use a global entropy production. 

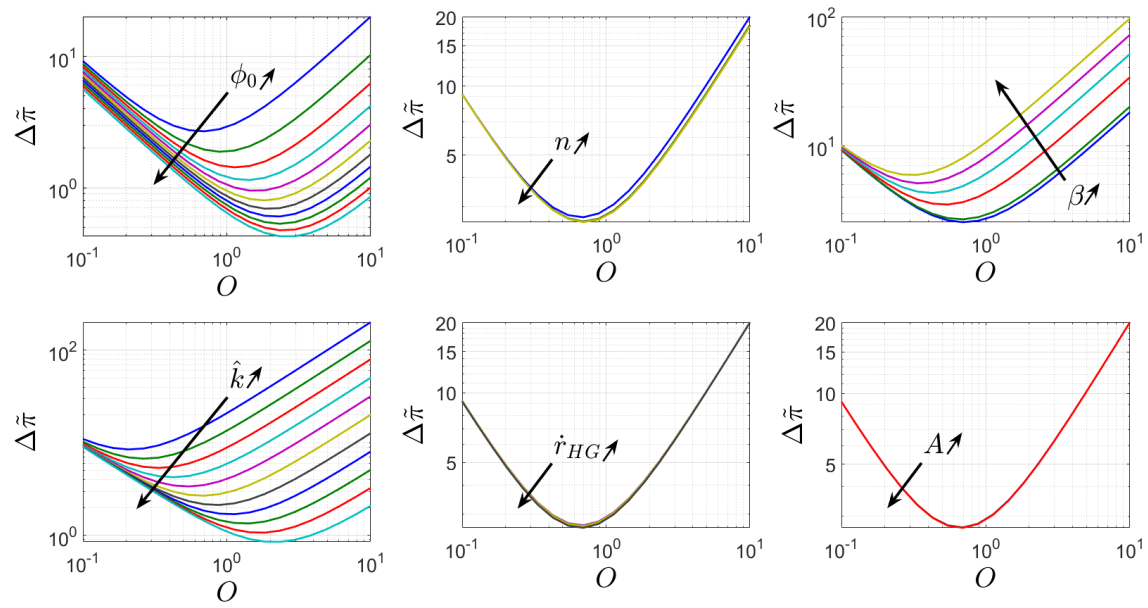

Figure 3: Evolution of the non dimensional entropy production $(\Delta \tilde{\pi})$ as a function of the aspect ratio $\left(O=l_{0} / h_{0}\right)$. Reference case: $\phi_{0}=0.05-n=1-\beta=1-\hat{k}=200$ $\dot{r}_{H G} \approx 31.6 \mathrm{Wm}^{-3} \mathrm{~K}^{-1}-A \approx 0.22 \mathrm{~m}^{2}$.

\subsection{Global optimum}

The global entropy production requires the integration over the studied surface:

$$
\begin{gathered}
\dot{\pi}_{H G A}=\int_{y=0}^{h_{0}-d_{0}} \int_{x=0}^{l_{0}} \dot{\Pi}_{H G A} d x d y \quad \dot{\pi}_{C S}=\int_{y=0}^{d_{0}} \int_{x=0}^{l_{0}} \dot{\Pi}_{C S} d x d y \\
\dot{\pi}=\dot{\pi}_{H G A}+\dot{\pi}_{C S}
\end{gathered}
$$

The integration is obtained numerically using a quadratic adaptative method and permits to calculate the global entropy produced in the plate for various parameters given previously. To compare the evolution of the optimal shape ratio, we use the dimensionless global entropy:

$$
\tilde{\pi}=\frac{\dot{\pi}}{\left(\frac{\dot{r}_{H G}}{T_{0}}\right)^{2}\left(\frac{h_{0} l_{0}}{k_{0}}\right)}
$$

The results obtained in fig. 4 show that the global entropy production optimum is not necessary the same as the one optimizing the entropy production fluxes difference at the extremities. Furthermore, it is possible to search for cases where a global equipartition $\left(\dot{\pi}_{H G A}=\dot{\pi}_{C S}\right)$ is possible, the 

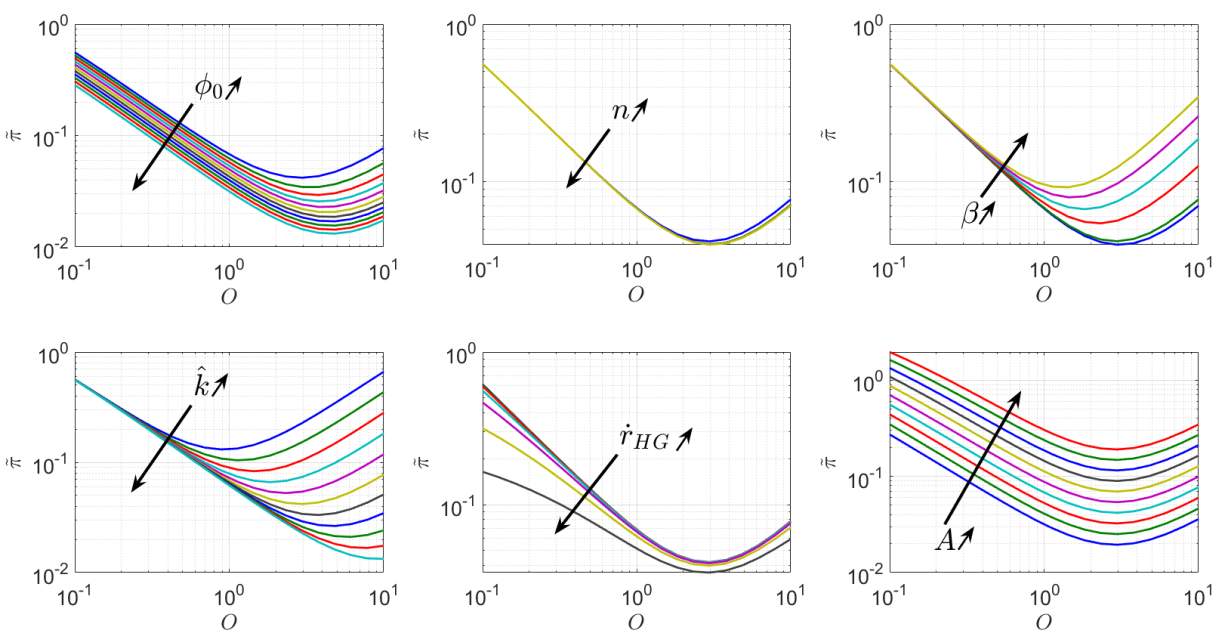

Figure 4: Evolution of the global dimensionless entropy production $(\tilde{\pi})$ as a function of the aspect ratio $\left(O=l_{0} / h_{0}\right)$. Reference case: $\phi_{0}=0.05-n=1-\beta=1-\hat{k}=200-$ $\dot{r}_{H G} \approx 31.6 \mathrm{Wm}^{-3} \mathrm{~K}^{-1}-A \approx 0.22 \mathrm{~m}^{2}$.
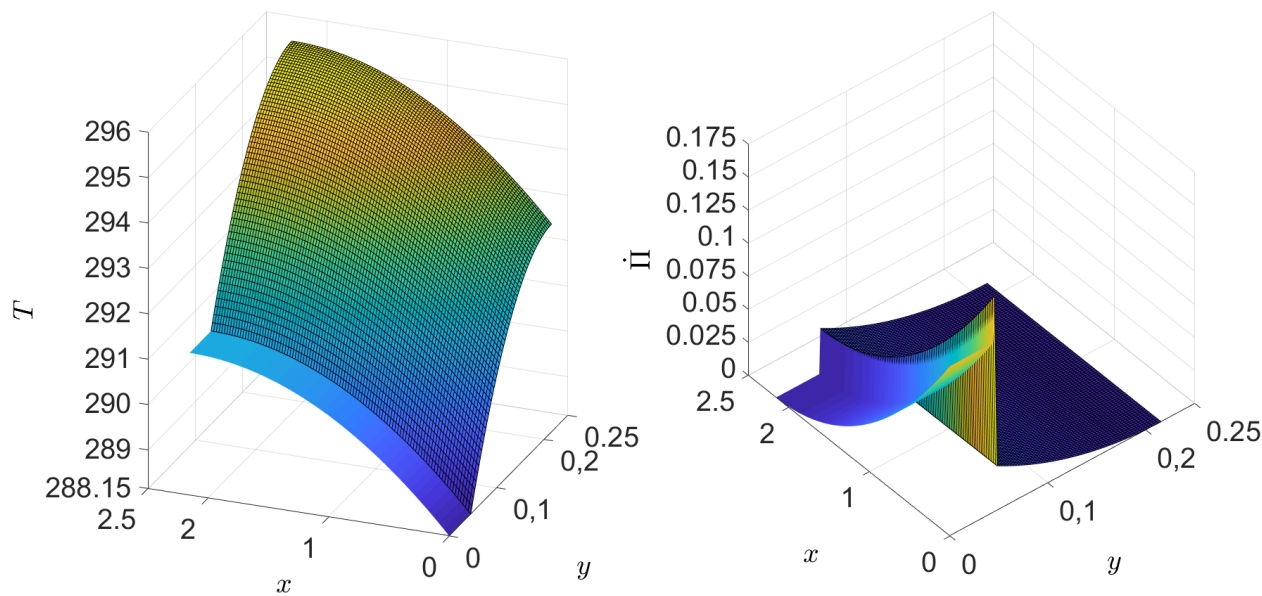

Figure 5: Temperature and local entropy production distribution in the heat generating plate for equipartition of global entropy production in HGA and CS. Obtained with: $\phi_{0}=0.21-n \approx 15.4-\beta=25-\hat{k} \approx 1262-\dot{r}_{H G} \approx 316 \mathrm{Wm}^{-3} \mathrm{~K}^{-1}-l_{0} \approx 2.15 \mathrm{~m}-$ $h_{0} \approx 0.22 \mathrm{~m}$. 
case we found in the framework of our study, which evenly distribute global entropy production in each part is shown in fig.5. Even if this case shows equipartition of global entropy production, it does not necessarily correspond to a minimum of the global entropy production of the entire plate.

\section{Dimensionless numbers for heat generating plates}

\subsection{Contibution analysis}

As usually used, dimensionless numbers are very powerful through their bond with the physics of the phenomena. Many dimensionless numbers are used and serve to emerge the properties of the phenomena under study. In our case, we choose the Ostrogradsky number which is a particularly fundamental number (see Appendix A) relating, in heat transfer, heat source amplitude in the volume and heat conducted through a characteristic length in the volume. In fact, in this particular case, this dimensionless number is comparable to the dimensionless temperature used in the framework of constructal theory in the heat generating plate problem, more precisely, the dimensionless temperature is inversely related to the Ostrogradski number:

$$
\frac{\left(T_{\max }-T_{\min }\right)}{\left(\frac{\dot{r} L^{2}}{k}\right)} \propto\left(\frac{1}{O s}\right) \Rightarrow \frac{1}{O s}=\frac{\left(T\left(l_{0}, h_{0}-d_{0}\right)-T_{0}\right)}{\frac{\dot{r}_{H G} h_{0} l_{0}}{k_{0}}}
$$

Besides the preceding number, one can use numbers representing each subpart of the plate as if they were independent of each other:

$$
O s_{C S i}=\frac{\dot{r}_{C S}\left(d_{0} l_{0}\right)}{k_{C S}\left(T\left(l_{0}, 0\right)-T_{0}\right)} \quad O s_{H G A i}=\frac{\dot{r}_{H G}\left(\left(h_{0}-d_{0}\right) l_{0}\right)}{k_{0}\left(T\left(l_{0}, h_{0}-d_{0}\right)-T\left(l_{0}, 0\right)\right)}
$$

Analogously, for the entire plate, we rather use an equivalent Ostrogradski representing the mean behaviour of the plate:

$$
O s_{G}=\frac{\dot{r_{G}}\left(h_{0} l_{0}\right)}{k_{G}\left(T\left(l_{0}, h_{0}-d_{0}\right)-T_{0}\right)}
$$

These numbers will be better used in the possible correlation between heat source amplitude and entropy production. 


\subsection{Ostrogradski correlation}

A property between dimensionless numbers involved in a phenomenon is that they can be bonded by correlations. In the framework of the second law, one can consider that a relation exists between the heat source generated in the plate surface and the heat dissipated by irreversibility:

$$
O s(\dot{r}) \sim C_{1} O s(T \dot{\Pi})^{m_{1}} \quad O s(T \dot{\Pi})=\frac{T \dot{\Pi}(\delta x)^{2}}{k \delta T}=\frac{\dot{\Pi}(\delta x)^{2}}{k} \cdot \frac{1}{C a}
$$

Where we can see the Carnot number in the Ostrogradski number based on the disspated energy. Thus, to simplify, one can study the correlation between an exergetic Ostrogradski number $\left(O_{X}\right)$ and an irreversible number bonded to the entropy production $(I)$ :

$$
O_{X} \sim C_{2} I^{m_{2}} \quad I=\frac{\dot{\Pi}(\delta x)^{2}}{k}
$$

with:

$$
O_{X}=O s(\dot{r}) \cdot C a=\frac{\dot{r}(\delta x)^{2}}{k T}
$$

The correlation postulated here is considered on the surface mean numbers thus the quantities $\dot{\Pi}$ and $T$ are the mean values on the surface plate. Moreover, the correlation is tested on each subpart of the plate on the conductive strip and on the heat generating (considering the independent Ostrogradski numbers) as well as the entire plate (considering an equivalent Ostrogradski number):

- Conductive strip:

$$
\begin{gathered}
O_{X}=\frac{r_{C S} l_{0} d_{0}}{k_{C S} \bar{T}} \quad \bar{T}=\frac{1}{d_{0} l_{0}} \int_{0}^{d_{0}} \int_{0}^{l_{0}} T(x, y) d x d y \\
I=\frac{\overline{\dot{\Pi}} l_{0} d_{0}}{k_{C S}} \quad \overline{\dot{\Pi}}=\frac{1}{d_{0} l_{0}} \int_{0}^{d_{0}} \int_{0}^{l_{0}} \dot{\Pi}(x, y) d x d y
\end{gathered}
$$

- Heat generating area:

$$
\begin{gathered}
O_{X}=\frac{r_{H G A} l_{0}\left(h_{0}-d_{0}\right)}{k_{0} \bar{T}} \quad \bar{T}=\frac{1}{\left(h_{0}-d_{0}\right) l_{0}} \int_{0}^{h_{0}-d_{0}} \int_{0}^{l_{0}} T(x, y) d x d y \\
I=\frac{\overline{\dot{\Pi}} l_{0}\left(h_{0}-d_{0}\right)}{k_{0}} \quad \overline{\dot{\Pi}}=\frac{1}{\left(h_{0}-d_{0}\right) l_{0}} \int_{0}^{h_{0}-d_{0}} \int_{0}^{l_{0}} \dot{\Pi}(x, y) d x d y
\end{gathered}
$$


- Hole plate

$$
\begin{gathered}
O_{X}=\frac{\dot{r}_{G} l_{0} h_{0}}{k_{G} \bar{T}} \quad \bar{T}=\frac{1}{h_{0} l_{0}} \int_{0}^{h_{0}} \int_{0}^{l_{0}} T(x, y) d x d y \\
I=\frac{\overline{\dot{\Pi}} l_{0} h_{0}}{k_{G}} \quad \overline{\dot{\Pi}}=\frac{1}{h_{0} l_{0}} \int_{0}^{h_{0}} \int_{0}^{l_{0}} \dot{\Pi}(x, y) d x d y
\end{gathered}
$$

The results for each case give a fundamental relation between the two Ostrogradski numbers, the exergetic Ostrograski number varies as the square root of the irreversible Ostrogradski number (see tab.1 and fig.6):

$$
O_{X} \sim \sqrt{I}
$$

\begin{tabular}{|c|c|c|}
\cline { 2 - 3 } \multicolumn{1}{c|}{} & $C_{2}$ & $m_{2}$ \\
\hline Conductive strip & 0.331 & 0.461 \\
\hline Heat generating area & 1.160 & 0.448 \\
\hline Whole plate & 0.467 & 0.516 \\
\hline
\end{tabular}

Table 1: Coefficients obtained from linear the fit of $\log O_{X}=f(\log I)$

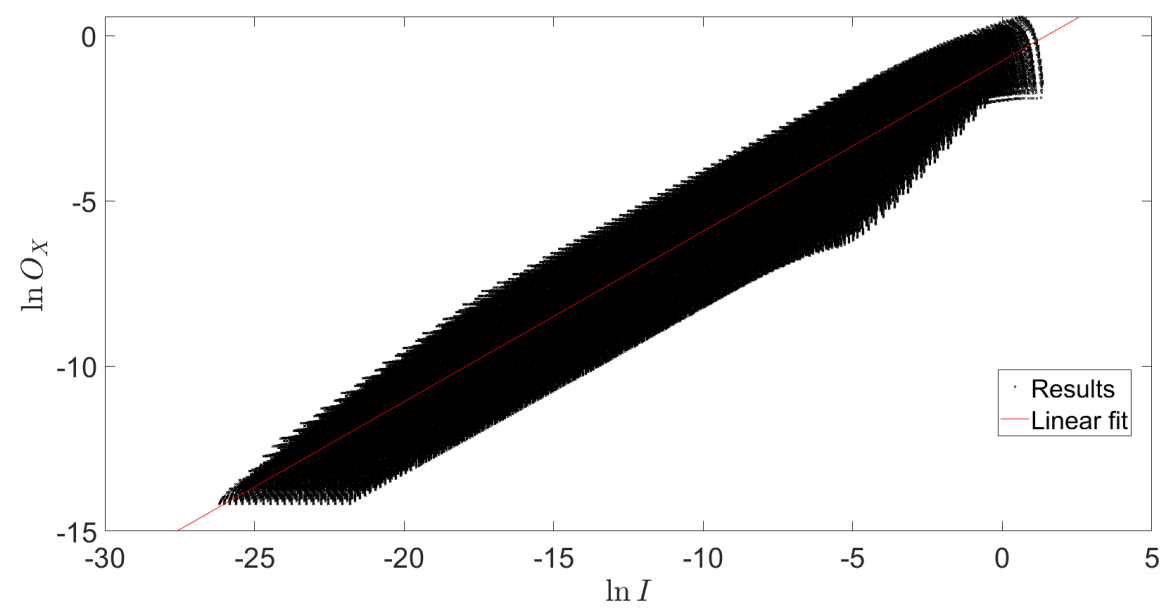

Figure 6: Logarithm of the exergetic Ostrogradski as a function of the logarithm of the irreversible Ostrogradski 


\section{Conclusion}

A study of the elemental construct of I-shapes conducting pathways has been conducted through entropy production. The entropy produced by irreversibility can be expressed using a thermodynamic scale related to a equivalent coefficient of performance. Using the constructal design method with the objective of minimizing the dimensionless maximum excess of entropy production leads to shape ratios different from the ones obtained minimizing the dimensionless maximum excess of temperature. Since entropy production is better defined as a global quantity, minimizing the dimensionless entropy production integrated on the surface leads to shape ratio optimums which are different from the previous optimums. Moreover, in this case, searching the equipartition in global entropy production (equality between the two entropy generated in each plate) does not necessary lead to a shape ratio optimum. Finally, the dimensionless maximum excess of temperature appears to be bonded to a particular dimensionless number known as the Ostrogradski number. A study between dimensionless numbers permits to correlate an exergetic Ostrogradski number (related to the heat source and the Carnot number) with an irreversible Ostrogradski number (related to the entropy production), more precisely, the exergetic Ostrogradski number evolves as the square root of the irreversible Ostrogradski number. Further work will be conducted on the constructal design method combining the objectives (the dimensionless maximum excess of temperature minimization and the dimensionless global entropy production minimization) and a study of the Ostrogradki number will be potentially applied to other domains of physics.

\section{Appendix A. On the Ostrogradski number}

We recall the two principles used in the context of heat transfer in order to show the emergence of dimensionless numbers:

$$
\rho C \frac{\partial T}{\partial t}=k \Delta T+\frac{h\left(T-T_{0}\right)}{L}+\dot{r} \quad \rho \frac{\partial S}{\partial t}=\frac{k \Delta T}{T}-k\left(\frac{\nabla T}{T}\right)^{2}+\frac{\dot{r}}{T}+\dot{\Pi}
$$

With:

$\rho$ : Density - $C$ : Heat capacity - $k$ : Heat conductivity $-\dot{r}:$ Heat source

$h:$ Convective heat transfer coefficient $-L:$ Characteristic length

Пं : Entropy generated by irreversibility 
A simple method to retrieve dimensionless numbers is to divide by the temporal term, leading to the natural apparition of the Fourier number $(\delta$ represents a variation):

$$
\frac{\left(k \frac{\delta T}{(\delta x)^{2}}\right)}{\left(\rho C \frac{\delta T}{\delta t}\right)} \propto \chi \frac{\delta t}{(\delta x)^{2}} \propto F_{O}
$$

Using $L \sim \delta x$ and using the Fourier number leads to:

$$
\frac{h \frac{\delta T}{L}}{\left(\rho C \frac{\delta T}{\delta t}\right)} \propto \frac{h \delta t}{\rho C \delta x} \propto B i F_{O} \quad \frac{\dot{r}}{\left(\rho C \frac{\delta T}{\delta t}\right)} \propto \dot{r} \frac{(\delta x)^{2}}{k \delta T} F_{O}
$$

The second principle leads also to the Fourier number (using $T \delta S \propto C \delta T$ ) and likewise reusing the Fourier number in the other parts leads to known dimensionless numbers:

$$
\begin{aligned}
& \frac{\left(\frac{k \delta T}{T(\delta x)^{2}}\right)}{\left(\rho \frac{\delta S}{\delta t}\right)} \propto F_{O} \\
& \frac{\frac{k}{T^{2}}\left(\frac{\delta T}{\delta x}\right)^{2}}{\left(\rho \frac{\delta S}{\delta t}\right)} \propto F_{O}\left(\frac{\delta T}{T}\right) \propto F_{O} C a
\end{aligned}
$$

Where we consider $C a$ as the Carnot number.

$$
\frac{\left(\frac{\dot{r}}{T}\right)}{\left(\rho \frac{\delta S}{\delta t}\right)} \propto \dot{r} \frac{(\delta x)^{2}}{k \delta T} F_{O} \quad 1 \propto \frac{\dot{\Pi}}{\left(\rho \frac{\delta S}{\delta t}\right)} \propto T \dot{\Pi} \frac{(\delta x)^{2}}{k \delta T} F_{O}
$$

It appears here that the Fourier number is a fundamental dimensionless number. This particular number can be used to simplify the other dimensionless numbers. In fact, we note more precisely that every dimensionless 
number can be expressed using the Fourier number and another important dimensionless number, the Ostrogradski number.

Analogously, this feature can be highlighted in fluid mechanics equations. The equation of the generalised Ostrogradski number and generalised Fourier number is:

$$
O s_{G}=\frac{S o(\delta x)^{2}}{a \delta b} \quad F o_{G}=\frac{C \delta t}{(\delta x)^{2}}
$$

Where $S o$ is a source (heat, motion quantity...) and $a$ and $b$ are the parameters bonded to the phenomenon studied (conductivity, dynamic viscosity and velocity and temperature). $C$ is also a parameter bonded to the phenomenon (diffusivity, kinematic viscosity). The interesting feature is that we can reduce all the components to sources, for example using $\dot{r}=h \delta T / L$ :

$$
O s_{G}=\frac{h \delta T}{L} \frac{(\delta x)^{2}}{k \delta T} \quad L \sim \delta x \quad O s_{G}=\frac{h \delta x}{k}=B i
$$

From this observation, one can generate any dimensionless number using a ratio of generalised dimensionless groups. For example, the Prandtl number is the ratio of the fluid Fourier to the thermal Fourier number. The Bejan number can be obtained using an Ostrogradski considering the pressure gradient $(\delta P / \delta x)$ as the source and dividing it by the thermal Fourier number (with $\delta v=\delta x / \delta t)$ :

$$
O s_{B E}=\frac{\delta P}{\delta x} \frac{(\delta x)^{2}}{\mu \delta v} \quad \frac{O s_{B E}}{F_{O}}=\frac{\delta P \delta x}{\mu \delta v} \frac{(\delta x)^{2}}{\chi \delta t}=\frac{\delta P(\delta x)^{2}}{\mu \chi}=\frac{\rho \delta P(\delta x)^{2}}{\nu \chi}=B e
$$

To summarize, using the generalised Fourier and Ostrogradski numbers permits to construct all the possibilities in terms of dimensionless numbers. 


\section{References}

[1] M. Feidt, The history and perspectives of efficiency at maximum power of the carnot engine, Entropy 19 (7). doi:10.3390/e19070369.

URL http://www.mdpi .com/1099-4300/19/7/369

[2] Z. Kolenda, J. Donizak, J. Hubert, On the minimum entropy production in steady state heat conduction processes, Energy 29 (12) (2004) 2441 - 2460, efficiency, Costs, Optimization, Simulation and Environmental Impact of Energy Systems. doi:https://doi.org/10.1016/j.energy.2004.03.049.

URL http://www.sciencedirect.com/science/article/pii/ S0360544204001288

[3] P. Ribeiro, D. Queiros-Condé, L. Grosu, L. Gallimard, An exergetic approach for materials fatigue, International Journal of Exergy 22 (3) (2017) 235 - 249. doi:10.1504/I JEX.2017.083172.

[4] A. Bejan, Street network theory of organization in nature, Journal of Advanced Transportation 30 (2) (1996) 85-107. arXiv:https: //onlinelibrary.wiley.com/doi/pdf/10.1002/atr.5670300207, doi:10.1002/atr.5670300207.

URL https://onlinelibrary.wiley.com/doi/abs/10.1002/atr. 5670300207

[5] A. Bejan, Constructal-theory network of conducting paths for cooling a heat generating volume, International Journal of Heat and Mass Transfer 40 (4) (1997) 799 - 816, (Published November 1, 1996). doi:https://doi.org/10.1016/0017-9310(96)00175-5.

URL http://www.sciencedirect.com/science/article/pii/ 0017931096001755

[6] A. Bejan, S. Lorente, The constructal law of design and evolution in nature, Philosophical Transactions of the Royal Society B: Biological Sciences 365 (1545) (2010) 1335-1347. arXiv:http://rstb. royalsocietypublishing.org/content/365/1545/1335.full.pdf, doi:10.1098/rstb.2009.0302.

URL http://rstb.royalsocietypublishing.org/content/365/ $1545 / 1335$ 
[7] A. Bejan, A. H. Reis, Thermodynamic optimization of global circulation and climate, International Journal of Energy Research 29 (4) (2005) 303316. doi:10.1002/er.1058.

URL http://dx.doi.org/10.1002/er.1058

[8] A. H. Reis, Use and validity of principles of extremum of entropy production in the study of complex systems, Annals of Physics 346 (Supplement C) (2014) 22 - 27. doi:https: //doi.org/10.1016/j.aop.2014.03.013.

URL http://www.sciencedirect.com/science/article/pii/ S0003491614000682

[9] A. H. Reis, A. F. Miguel, M. Aydin, Constructal theory of flow architecture of the lungs, Medical Physics 31 (5) (2004) 1135-1140. doi: 10.1118/1.1705443.

URL http://dx.doi.org/10.1118/1.1705443

[10] T. Wattez, S. Lorente, From pore network prediction based on the constructal law to macroscopic properties of porous media, Journal of Physics D: Applied Physics 48 (48) (2015) 485503.

URL http://stacks.iop.org/0022-3727/48/i=48/a=485503

[11] A. Bejan, R. Chen, S. Lorente, C. Y. Wen, Hierarchy in air travel: Few large and many small, Journal of Applied Physics 122 (2) (2017) 024904. doi:10.1063/1.4993580.

[12] A. Bejan, S. Ziaei, S. Lorente, Distributed energy storage: Timedependent tree flow design, Journal of Applied Physics 119 (18) (2016) 184901. doi:10.1063/1.4948663.

[13] A. F. Miguel, Constructal branching design for fluid flow and heat transfer, International Journal of Heat and Mass Transfer 122 (2018) 204 - 211. doi:https://doi.org/10.1016/j.ijheatmasstransfer. 2018.01 .095$.

URL http://www.sciencedirect.com/science/article/pii/ S0017931017355710

[14] M. Alalaimi, S. Lorente, A. Bejan, Thermal coupling between a helical pipe and a conducting volume, International Journal of Heat and Mass Transfer 83 (2015) 762 - 767. doi:https: 
//doi.org/10.1016/j.ijheatmasstransfer.2014.12.058.

URL http://www.sciencedirect.com/science/article/pii/ S0017931014011661

[15] A. Bejan, M. Alalaimi, A. Sabau, S. Lorente, Entrance-length dendritic plate heat exchangers, International Journal of Heat and Mass Transfer 114 (2017) 1350 - 1356. doi:https: //doi.org/10.1016/j.ijheatmasstransfer.2017.06.094.

URL http://www.sciencedirect.com/science/article/pii/ S001793101731308X

[16] L. Chen, Progress in study on constructal theory and its applications, Science China Technological Sciences 55 (3) (2012) 802-820. doi:10. 1007/s11431-011-4701-9.

URL https://doi .org/10.1007/s11431-011-4701-9

[17] L. Chen, H. Feng, Z. Xie, F. Sun, Constructal optimization for leaf-like body based on maximization of heat transfer rate, International Communications in Heat and Mass Transfer 71 (2016) 157 - 163. doi: https://doi.org/10.1016/j.icheatmasstransfer.2015.12.022.

URL http://www.sciencedirect.com/science/article/pii/ S0735193315002705

[18] T. Kamps, M. Biedermann, C. Seidel, G. Reinhart, Design approach for additive manufacturing employing constructal theory for point-to-circle flows, Additive Manufacturing 20 (2018) 111 - 118. doi:https://doi.org/10.1016/j.addma.2017.12.005.

URL http://www.sciencedirect.com/science/article/pii/ S2214860417300349

[19] D. González, J. Amigo, S. Lorente, A. Bejan, F. Suárez, Constructal design of salt-gradient solar pond fields, International Journal of Energy Research 40 (10) 1428-1446. arXiv: https://onlinelibrary.wiley.com/doi/pdf/10.1002/er.3539, doi:10.1002/er.3539.

URL https://onlinelibrary.wiley.com/doi/abs/10.1002/er. 3539

[20] Y. Pan, S. Lorente, A. Bejan, L. Xia, S. Deng, Distribution of size in multi-evaporator air conditioning systems, Interna- 
tional Journal of Energy Research 38 (5) 652-657. arXiv: https://onlinelibrary.wiley.com/doi/pdf/10.1002/er.3072, doi:10.1002/er.3072.

URL https://onlinelibrary.wiley.com/doi/abs/10.1002/er. 3072

[21] L. A. O. Rocha, S. Lorente, A. Bejan, Vascular design for reducing hot spots and stresses, Journal of Applied Physics 115 (17) (2014) 174904. doi:10.1063/1.4874220.

[22] A. Bejan, S. Lorente, Constructal law of design and evolution: Physics, biology, technology, and society, Journal of Applied Physics 113 (15) (2013) 151301. arXiv:https://doi.org/10.1063/1.4798429, doi: $10.1063 / 1.4798429$.

URL https://doi.org/10.1063/1.4798429

[23] A. Bejan, Shape and Structure, from Engineering to Nature, Cambridge University Press, 2000.

[24] A. Bejan, A. Almerbati, S. Lorente, Economies of scale: The physics basis, Journal of Applied Physics 121 (4) (2017) 044907. doi:10.1063/ 1.4974962 .

[25] D. Queiros-Condé, J. Bonjour, W. Wechsatol, A. Bejan, Parabolic scaling of tree-shaped constructal network, Physica A: Statistical Mechanics and its Applications 384 (2) (2007) 719 - 724. doi:https://doi.org/10.1016/j.physa.2007.05.037.

URL http://www.sciencedirect.com/science/article/pii/ S037843710700550X

[26] D. Queiros-Condé, A diffusion equation to describe scale-and time-dependent dimensions of turbulent interfaces, Proceedings of the Royal Society of London A: Mathematical, Physical and Engineering Sciences 459 (2040) (2003) 3043-3059. arXiv:http://rspa. royalsocietypublishing.org/content/459/2040/3043.full.pdf, doi:10.1098/rspa.2003.1167.

URL http://rspa.royalsocietypublishing.org/content/459/ 2040/3043 
[27] P. Ribeiro, D. Queiros-Condé, A scale-entropy diffusion equation to explore scale-dependent fractality, Proceedings of the Royal Society of London A: Mathematical, Physical and Engineering Sciences 473 (2200). arXiv:http://rspa.royalsocietypublishing.org/content/473/ 2200/20170054.full.pdf, doi:10.1098/rspa.2017.0054.

URL http://rspa.royalsocietypublishing.org/content/473/ $2200 / 20170054$

[28] S. Ziaei, S. Lorente, A. Bejan, Morphing tree structures for latent thermal energy storage, Journal of Applied Physics 117 (22) (2015) 224901. doi:10.1063/1.4921442.

[29] M. Eslami, M. Bahrami, Sensible and latent thermal energy storage with constructal fins, International Journal of Hydrogen Energy 42 (28) (2017) 17681 - 17691, special Issue on The 4th European Conference on Renewable Energy Systems (ECRES 2016), 28-31 August 2016, Istanbul, Turkey. doi:https://doi.org/10.1016/j.ijhydene.2017.04.097.

URL http://www.sciencedirect.com/science/article/pii/ S0360319917314866

[30] S. Ziaei, S. Lorente, A. Bejan, Constructal design for convection melting of a phase change body, International Journal of Heat and Mass Transfer 99 (2016) 762 - 769. doi:https: //doi.org/10.1016/j.ijheatmasstransfer.2016.04.022.

URL http://www.sciencedirect.com/science/article/pii/ S0017931016304586

[31] S. Lorente, A. Bejan, J. Niu, Constructal design of latent thermal energy storage with vertical spiral heaters, International Journal of Heat and Mass Transfer 81 (2015) 283 - 288. doi:https: //doi.org/10.1016/j.ijheatmasstransfer.2014.09.077.

URL http://www.sciencedirect.com/science/article/pii/ S0017931014008813

[32] C. Lui, N. Fong, S. Lorente, A. Bejan, W. Chow, Constructal design of evacuation from a three-dimensional living space, Physica A: Statistical Mechanics and its Applications 422 (2015) 47 - 57. doi:https://doi.org/10.1016/j.physa.2014.12.005.

URL http://www.sciencedirect.com/science/article/pii/ S0378437114010401 
[33] C. H. Lui, N. K. Fong, S. Lorente, A. Bejan, W. K. Chow, Constructal design of pedestrian evacuation from an area, Journal of Applied Physics 113 (3) (2013) 034904. doi:10.1063/1.4780612.

[34] R. J. Klein, G. Lorenzini, F. S. Zinani, L. A. Rocha, Dimensionless pressure drop number for non-newtonian fluids applied to constructal design of heat exchangers, International Journal of Heat and Mass Transfer 115 (2017) 910 - 914. doi:https: //doi.org/10.1016/j.ijheatmasstransfer.2017.07.122.

URL http://www.sciencedirect.com/science/article/pii/ S0017931017314473

[35] A. Bejan, S. Lorente, L. Martins, J. P. Meyer, The constructal size of a heat exchanger, Journal of Applied Physics 122 (6) (2017) 064902. doi : $10.1063 / 1.4991014$.

[36] A. Bejan, S. Lorente, D.-H. Kang, Constructal design of regenerators, International Journal of Energy Research 37 (12) 1509-1518. arXiv: https://onlinelibrary.wiley.com/doi/pdf/10.1002/er.2960, doi:10.1002/er.2960.

URL https://onlinelibrary.wiley.com/doi/abs/10.1002/er. 2960

[37] G. Xie, J. Liu, W. Zhang, G. Lorenzini, C. Biserni, Numerical prediction of flow structure and heat transfer in square channels with dimples combined with secondary half-size dimples/protrusions, Numerical Heat Transfer, Part A: Applications 65 (4) (2014) 327356. arXiv:https://doi.org/10.1080/10407782.2013.832073, doi: $10.1080 / 10407782.2013 .832073$.

URL https://doi.org/10.1080/10407782.2013.832073

[38] L. Hermany, G. Lorenzini, R. Klein, F. Zinani, E. D. dos Santos, L. A. Isoldi, L. A. O. Rocha, Constructal design applied to elliptic tubes in convective heat transfer cross-flow of viscoplastic fluids, International Journal of Heat and Mass Transfer 116 (2018) 1054 - 1063. doi :https: //doi.org/10.1016/j.ijheatmasstransfer.2017.09.108.

URL http://www.sciencedirect.com/science/article/pii/ S0017931017321385 
[39] G. Lorenzini, M. Medici, L. A. O. Rocha, Convective analysis of constructal t-shaped fins, Journal of Engineering Thermophysics 23 (2) (2014) 98-104. doi:10.1134/S1810232814020027.

URL https://doi.org/10.1134/S1810232814020027

[40] Y. Song, M. Asadi, G. Xie, L. A. O. Rocha, Constructal wavyfin channels of a compact heat exchanger with heat transfer rate maximization and pressure losses minimization, Applied Thermal Engineering 75 (2015) 24 - 32. doi:https: //doi.org/10.1016/j.applthermaleng.2014.05.027.

URL http://www.sciencedirect.com/science/article/pii/ S1359431114003883

[41] G. Lorenzini, C. Biserni, F. L. Garcia, L. A. O. Rocha, Geometric optimization of a convective t-shaped cavity on the basis of constructal theory, International Journal of Heat and Mass Transfer 55 (23) (2012) 6951 - 6958. doi:https: //doi.org/10.1016/j.ijheatmasstransfer.2012.07.009.

URL http://www.sciencedirect.com/science/article/pii/ S0017931012005364

[42] F. Teixeira, G. Lorenzini, M. Errera, L. Rocha, L. Isoldi, E. dos Santos, Constructal design of triangular arrangements of square bluff bodies under forced convective turbulent flows, International Journal of Heat and Mass Transfer 126 (2018) 521 - 535. doi:https: //doi.org/10.1016/j.ijheatmasstransfer.2018.04.134.

URL http://www.sciencedirect.com/science/article/pii/ S001793101831072X

[43] A. Razera, R. da Fonseca, L. Isoldi, E. dos Santos, L. Rocha, C. Biserni, Constructal design of a semi-elliptical fin inserted in a lid-driven square cavity with mixed convection, International Journal of Heat and Mass Transfer 126 (2018) 81 - 94. doi:https: //doi.org/10.1016/j.ijheatmasstransfer.2018.05.157.

URL http://www.sciencedirect.com/science/article/pii/ S0017931018313516

[44] B. Feijó, G. Lorenzini, L. Isoldi, L. Rocha, J. Goulart, E. dos Santos, Constructal design of forced convective flows in channels 
with two alternated rectangular heated bodies, International Journal of Heat and Mass Transfer 125 (2018) 710 - 721. doi:https: //doi.org/10.1016/j.ijheatmasstransfer.2018.04.086.

URL http://www.sciencedirect.com/science/article/pii/ S0017931018308639

[45] A. Almerbati, S. Lorente, A. Bejan, The evolutionary design of cooling a plate with one stream, International Journal of Heat and Mass Transfer 116 (2018) 9 - 15 . doi:https: //doi.org/10.1016/j.ijheatmasstransfer.2017.08.122.

URL http://www.sciencedirect.com/science/article/pii/ S0017931017318069

[46] G. Lorenzini, C. Biserni, R. L. Correa, E. D. dos Santos, L. A. Isoldi, L. A. O. Rocha, Constructal design of tshaped assemblies of fins cooling a cylindrical solid body, International Journal of Thermal Sciences 83 (2014) $96-103$. doi:https://doi.org/10.1016/j.ijthermalsci.2014.04.011.

URL http://www.sciencedirect.com/science/article/pii/ S1290072914000982

[47] C. Biserni, F. L. Dalpiaz, T. M. Fagundes, L. A. O. Rocha, Constructal design of t-shaped morphing fins coupled with a trapezoidal basement: A numerical investigation by means of exhaustive search and genetic algorithm, International Journal of Heat and Mass Transfer 109 (2017) 73 - 81. doi:https: //doi.org/10.1016/j.ijheatmasstransfer.2017.01.033.

URL http://www.sciencedirect.com/science/article/pii/ S0017931016325753

[48] J. C. B. Vianna, E. da Silva Diaz Estrada, L. A. Isoldi, E. D. dos Santos, J. A. Souza, A new constructal theory based algorithm applied to thermal problems, International Journal of Thermal Sciences 126 (2018) 118 - 124. doi:https://doi.org/10.1016/j.ijthermalsci.2017.12.023.

URL http://www.sciencedirect.com/science/article/pii/ S1290072917321075

[49] C. Biserni, F. L. Dalpiaz, T. M. Fagundes, M. Garai, L. A. O. Rocha, Geometric optimization of morphing fins coupled with 
a semicircular heat generating body: A numerical investigation on the basis of bejan's theory, International Communications in Heat and Mass Transfer 86 (2017) 81 - 91. doi:https: //doi.org/10.1016/j.icheatmasstransfer.2017.05.006.

URL http://www.sciencedirect.com/science/article/pii/ S0735193317300969

[50] H. Feng, L. Chen, Z. Xie, F. Sun, Constructal design for helm-shaped fin with internal heat sources, International Journal of Heat and Mass Transfer 110 (2017) 1 - 6. doi:https: //doi.org/10.1016/j.ijheatmasstransfer.2017.02.074.

URL http://www.sciencedirect.com/science/article/pii/ S001793101634056X

[51] G. Lorenzini, R. L. Corrêa, E. D. dos Santos, L. A. O. Rocha, Constructal design of complex assembly of fins, Journal of Heat Transfer 133 (2011) 081902-081902-7. doi:10.1115/1.4003710.

URL http://dx.doi.org/10.1115/1.4003710

[52] G. Lorenzini, E. da Silva Diaz Estrada, E. D. dos Santos, L. A. Isoldi, L. A. O. Rocha, Constructal design of convective cavities inserted into a cylindrical solid body for cooling, International Journal of Heat and Mass Transfer 83 (2015) 75 - 83. doi:https: //doi.org/10.1016/j.ijheatmasstransfer.2014.11.065.

URL http://www.sciencedirect.com/science/article/pii/ S0017931014010539

[53] H. Kobayashi, T. Maeno, S. Lorente, A. Bejan, Double tree structure in a conducting body, International Journal of Heat and Mass Transfer 77 (2014) 140 - 146. doi:https: //doi.org/10.1016/j.ijheatmasstransfer.2014.04.072.

URL http://www.sciencedirect.com/science/article/pii/ S0017931014003901

[54] L. Kuddusi, J. C. Denton, Analytical solution for heat conduction problem in composite slab and its implementation in constructal solution for cooling of electronics, Energy Conversion and Management 48 (4) (2007) 1089 - 1105. doi:https: //doi.org/10.1016/j.enconman.2006.10.024. 
URL http://www.sciencedirect.com/science/article/pii/ S0196890406003396

[55] L. Kuddusi, N. Eğrican, A critical review of constructal theory, Energy Conversion and Management 49 (5) (2008) 1283 - 1294. doi:https://doi.org/10.1016/j.enconman.2007.05.023.

URL http://www.sciencedirect.com/science/article/pii/ S0196890407002622

[56] L. Ghodoossi, N. Eğrican, Exact solution for cooling of electronics using constructal theory, Journal of Applied Physics 93 (8) (2003) 49224929. arXiv:https://doi.org/10.1063/1.1562008, doi:10.1063/1. 1562008.

URL https://doi.org/10.1063/1.1562008

[57] W. Wu, L. Chen, F. Sun, On the "area to point" flow problem based on constructal theory, Energy Conversion and Management 48 (1) (2007) 101 - 105. doi : https://doi .org/10.1016/j.enconman.2006.05.009. URL http://www.sciencedirect.com/science/article/pii/ S0196890406001695

[58] P. Ribeiro, D. Queiros-Condé, The space and time behaviour of the constructal plate generating heat, International Journal of Thermal Sciences 135 (2019) 173 - 186. doi:https: //doi.org/10.1016/j.ijthermalsci.2018.08.045.

URL http://www.sciencedirect.com/science/article/pii/ S1290072918309694

[59] H. Feng, L. Chen, Z. Xie, F. Sun, Constructal design for "+" shaped high conductivity pathways over a square body, International Journal of Heat and Mass Transfer 91 (2015) 162 - 169. doi:https: //doi.org/10.1016/j.ijheatmasstransfer.2015.07.105.

URL http://ww..sciencedirect.com/science/article/pii/ S0017931015008236

[60] C. Biserni, L. A. O. Rocha, G. Stanescu, E. Lorenzini, Constructal h-shaped cavities according to bejan's theory, International Journal of Heat and Mass Transfer 50 (11) (2007) 2132 - 2138. doi:https: //doi.org/10.1016/j.ijheatmasstransfer.2006.11.006. 
URL http://www.sciencedirect.com/science/article/pii/ S001793100600620X

[61] G. Lorenzini, C. Biserni, L. A. O. Rocha, Constructal design of x-shaped conductive pathways for cooling a heat-generating body, International Journal of Heat and Mass Transfer 58 (1) (2013) 513 - 520. doi: https://doi.org/10.1016/j.ijheatmasstransfer.2012.11.040.

URL http://www.sciencedirect.com/science/article/pii/ S0017931012009039

[62] C. dos Santos Horbach, E. D. dos Santos, L. A. Isoldi, L. A. O. Rocha, Constructal design of y-shaped conductive pathways for cooling a heatgenerating body, Defect and Diffusion Forum 348 (2014) 245-260. doi : 10.4028/www.scientific.net/DDF.348. 245.

[63] M. R. Hajmohammadi, G. Lorenzini, O. J. Shariatzadeh, C.Biserni, Evolution in the design of v-shaped highly conductive pathways embedded in a heat-generating piece, Journal of Heat Transfer 137 (2015) 061001061001-7. doi:10.1115/1.4029847.

URL http://dx.doi.org/10.1115/1.4029847

[64] E. da S. D. Estrada, T. M. Fagundes, L. A. Isoldi, E. D. dos Santos, G. Xie, L. A. O. Rocha, Constructal design associated to genetic algorithm of asymmetric v-shaped pathways, Journal of Heat Transfer 137 (2015) 061010-061010-7. doi:10.1115/1.4029868.

URL http://dx.doi.org/10.1115/1.4029868

[65] M. Hajmohammadi, V. A. Abianeh, M. Moezzinajafabadi, M. Daneshi, Fork-shaped highly conductive pathways for maximum cooling in a heat generating piece, Applied Thermal Engineering 61 (2) (2013) 228 - 235. doi:https://doi.org/10.1016/j.applthermaleng.2013.08.001.

URL http://www.sciencedirect.com/science/article/pii/ S1359431113005565

[66] G. Lorenzini, E. X. Barreto, C. C. Beckel, P. S. Schneider, L. A. Isoldi, E. D. dos Santos, L. A. O. Rocha, Geometrical evaluation of t-shaped high conductive pathway with thermal contact resistance for cooling of heat-generating medium, International Journal of Heat and Mass Transfer 108 (2017) 1884 - 1893. doi:https: //doi.org/10.1016/j.ijheatmasstransfer.2017.01.008. 
URL http://www.sciencedirect.com/science/article/pii/ S0017931016325972

[67] G. Lorenzini, E. X. Barreto, C. C. Beckel, P. S. Schneider, L. A. Isoldi, E. D. dos Santos, L. A. O. Rocha, Constructal design of i-shaped high conductive pathway for cooling a heat-generating medium considering the thermal contact resistance, International Journal of Heat and Mass Transfer 93 (2016) 770 - 777. doi:https: //doi.org/10.1016/j.ijheatmasstransfer.2015.10.015.

URL http://www.sciencedirect.com/science/article/pii/ S0017931015010133

[68] Q. Xiao, L. Chen, F. Sun, Constructal optimization for "disc-to-point" heat conduction without the premise of optimized last-order construct, International Journal of Thermal Sciences 50 (6) (2011) 1031 - 1036. doi:https://doi.org/10.1016/j.ijthermalsci.2011.01.016.

URL http://www.sciencedirect.com/science/article/pii/ S1290072911000251

[69] L. Chen, H. Feng, Z. Xie, F. Sun, Constructal optimization for "disc-point" heat conduction at micro and nanoscales, International Journal of Heat and Mass Transfer 67 (2013) 704 - 711. doi:https: //doi.org/10.1016/j.ijheatmasstransfer.2013.08.051.

URL http://www.sciencedirect.com/science/article/pii/ S0017931013007126

[70] H. Feng, L. Chen, Z. Xie, F. Sun, "volume-point" heat conduction constructal optimization based on minimization of maximum thermal resistance with triangular element at micro and nanoscales, Journal of the Energy Institute 89 (2) (2016) $302-312$. doi:https://doi.org/10.1016/j.joei.2015.01.016.

URL http://www.sciencedirect.com/science/article/pii/ S1743967115000033

[71] J. You, H. Feng, L. Chen, Z. Xie, Heat conduction constructal optimization for nonuniform heat generating area based on triangular element, International Journal of Heat and Mass Transfer 117 (2018) 896 - 902. doi:https://doi.org/10.1016/j.ijheatmasstransfer. 2017.10 .032 . 
URL http://www.sciencedirect.com/science/article/pii/ S0017931017331824

[72] E. Cetkin, A. Oliani, The natural emergence of asymmetric tree-shaped pathways for cooling of a non-uniformly heated domain, Journal of Applied Physics 118 (2) (2015) 024902. arXiv:https://doi.org/10. 1063/1.4926620, doi:10.1063/1.4926620.

URL https://doi.org/10.1063/1.4926620

[73] J. A. Souza, J. C. Ordonez, Constructal Design of High-Conductivity Inserts, Springer New York, New York, NY, 2013, pp. 91-111. doi: 10.1007/978-1-4614-5049-8_6.

URL https ://doi .org/10.1007/978-1-4614-5049-8_6

[74] P. Avendaño, J. Souza, D. Adamatti, Construction of conductive pathways using genetic algorithms and constructal theory, International Journal of Thermal Sciences 134 (2018) $200-207$. doi:https://doi.org/10.1016/j.ijthermalsci.2018.08.013.

URL http://www.sciencedirect.com/science/article/pii/ S1290072918305477

[75] X. Xu, X. Liang, J. Ren, Optimization of heat conduction using combinatorial optimization algorithms, International Journal of Heat and Mass Transfer 50 (9) (2007) 1675 - 1682. doi:https: //doi.org/10.1016/j.ijheatmasstransfer.2006.10.037.

URL http://www.sciencedirect.com/science/article/pii/ S0017931006006156

[76] B. Li, J. Hong, L. Ge, Constructal design of internal cooling geometries in heat conduction system using the optimality of natural branching structures, International Journal of Thermal Sciences 115 (2017) 16 28. doi:https://doi.org/10.1016/j.ijthermalsci.2017.01.007.

URL http://www.sciencedirect.com/science/article/pii/ S1290072916309851

[77] S. Tescari, N. Mazet, P. Neveu, Constructal theory through thermodynamics of irreversible processes framework, Energy Conversion and Management 52 (10) (2011) 3176 - 3188. doi:https://doi.org/10.1016/j.enconman.2011.04.025. 
URL http://www.sciencedirect.com/science/article/pii/ S0196890411001567

[78] J. Lewins, Bejan's constructal theory of equal potential distribution, International Journal of Heat and Mass Transfer 46 (9) (2003) 1541 1543. doi:https://doi.org/10.1016/S0017-9310(02)00441-6.

URL http://www.sciencedirect.com/science/article/pii/ S0017931002004416

[79] L. Ghodoossi, Entropy generation rate in uniform heat generating area cooled by conducting paths: criterion for rating the performance of constructal designs, Energy Conversion and Management 45 (18) (2004) 2951 - 2969. doi:https: //doi.org/10.1016/j.enconman.2003.12.001.

URL http://www.sciencedirect.com/science/article/pii/ S0196890403003807

[80] S. Wei, L. Chen, F. Sun, The area-point constructal optimization for discrete variable cross-section conducting path, Applied Energy 86 (7) (2009) 1111 - $1118 . \quad$ doi:https: //doi.org/10.1016/j.apenergy.2008.06.010.

URL http://www.sciencedirect.com/science/article/pii/ S030626190800161X

[81] Y. Canivet, D. Queiros-Condé, L. Grosu, Fractal representation of exergy, Entropy 18 (2). doi:10.3390/e18020056.

URL http://www . mdpi . com/1099-4300/18/2/56 